\title{
CORPOS FEMININOS EM DEBATE: SER MULHER NA GINÁSTICA RÍTMICA
}

\author{
A DEBATE ABOUT FEMININE BODIES: TO BE WOMAN IN RHYTHMIC \\ GYMNASTICS
}

CUERPOS FEMENINOS EN DEBATE: SER MUJER EN LA GIMNASIA

RÍTMICA

\section{Patrícia Luiza Bremer Boaventura*, Alexandre Fernandez Vaz*}

Palavras chave: Corpo Humano.

Gênero.

Esportes.

Ginástica Rítmica.

Keywords: Human Body.

Gender.

Sports.

Rhythmic

Gymnastics.

Palabras clave: Cuerpo Humano. Género;

Deportes.

Gimnasia Rítmica.
Resumo: Tomando como referência observações e discursos de atletas e treinadoras de ginástica rítmica (GR), por meio da etnografia como perspectiva metodológica, busca-se discutir algumas das múltiplas inscrições nos corpos femininos e algumas de suas representações. Demarcam-se tipos de feminilidades nessa modalidade esportiva em que os corpos são educados e apresentam características que nos ajudam a refletir os padrões de feminilidade. As análises deste estudo contribuem para um debate acerca das relações de gênero no esporte, incorporação e reprodução de discursos referentes ao corpo feminino e os contrapontos entre feminilidades e masculinidades.

Abstract: Based on observations and discourses of rhythmic gymnastics (GR) athletes and coaches, with ethnography as a methodological perspective, we discuss some of the multiple inscriptions on female bodies and some of their representations. Types of femininities are distinguished in that sport in which bodies are educated and present characteristics that help us reflect femininity patterns. The analyses in this study contribute to a debate about gender relations in sports, incorporation and reproduction of discourses referring to the female body, and the counterpoints between femininities and masculinities.

Resumen: Tomando como referencia observaciones y discursos de atletas y entrenadoras de Gimnasia Rítmica (GR), con la etnografía como perspectiva metodológica, se busca discutir algunas de las múltiples inscripciones en los cuerpos femeninos y algunas de sus representaciones. Se delimitan tipos de feminidades en esa modalidad deportiva en que los cuerpos son educados y presentan características que nos ayudan a reflejar los patrones de feminidad. Los análisis de este estudio contribuyen a un debate acerca de las relaciones de género en el deporte, incorporación y reproducción de discursos referentes al cuerpo femenino y los contrapuntos entre feminidades y masculinidades.
* Universidade Federal de Santa Catarina, Florianópolis, SC, Brasil. E-mail:

cissaboaventura@gmail.com; alexfvaz@uol.com.br

Recebido em: 19-02-2019 Aprovado em: 03-09-2019 Publicado em: 11-02-2020 


\section{INTRODUÇÃO}

As categorias corpo e gênero estão implicadas em sistemas de significação e relações de poder, o que coloca em questão noções de identidades de gênero que se pretendem universais, absolutas, únicas. Nessa perspectiva, gênero está ligado à produção de identidades diversas e plurais de mulheres e homens no interior de relações e práticas sociais, não porque seriam assim em sua essência, mas porque fazem parte de uma construção cultural atravessada pelas representações de feminilidades e masculinidades, que inscrevem diferentes marcas nos corpos e por meio das quais são ensinados costumes, valores, crenças, maneiras de se perceber, ser e de agir como mulheres ou como homens (GOELLNER, 2016; LOURO, 2004).

Práticas sociais, como o esporte, "forjam e conformam comportamentos e subjetividades" (BRACHT, 2003, p. 21) e produzem distintos corpos que supõem padrões específicos e generificados como modelos de performances públicas esperadas para homens e para mulheres. As representações de masculinidades e feminilidades estão inscritas no corpo, marcando a pele e os modos de viver de homens e mulheres, as várias possibilidades de experimentar prazeres, dores, desejos. Deste modo, diferentes modalidades esportivas marcam corpos de formas distintas por exigirem padrões específicos conforme a execução técnica e estética exigidas. Isso é alcançado, via de regra, pelo treinamento.

Comumente apresentada como modalidade típica do mundo feminino, tanto em função de seus aspectos simbólicos quanto em relação às suas características técnicas e estéticas, a ginástica rítmica $(G R)$ é um esporte sobre o qual o discurso nativo costuma dizer que estão aliados a arte do movimento expressivo do corpo com a utilização ou não de aparelhos (corda, bola, arco, maças e fitas) e a interpretação de uma música, supondo-se formar uma síntese harmoniosa de elementos corporais técnicos e estéticos (BOAVENTURA, 2016).

A GR é caracterizada por ser um espaço no interior do qual leveza, beleza, graça e sensibilidade se apresentam como critérios indispensáveis para um elevado desempenho a enquadrar o feminino (GUÉRIOS, 1956 apud CORAT; ALMEIDA, 2012). Com raízes na Ginástica Moderna, surgindo no início do século $X X$, na Europa Central, como nova concepção de ginástica para mulher, a GR não é um método ou sistema, mas um "resultado de um movimento renovador que surgiu de uma necessidade de movimentos para o sexo feminino com uma dinâmica e ritmos diferentes" (ANGHEBEN, 2009, p. 47). ${ }^{1}$

Num esforço de verificar essas e outras singularidades na construção dos corpos femininos na GR e os atravessamentos de gênero que os produzem como atletas, o objetivo principal deste trabalho é apresentar aspectos de uma pedagogia dos corpos femininos que se materializa a partir da rotina de atletas e que tende a didatizar os movimentos e gestos técnicos, disciplinar e ensinar a sujeitar-se. Que ideias de mulher, na sua relação com a produção corporal, podem ser identificadas na GR? Neste esporte, "oficialmente" feminino, são evidenciadas apenas características ditas femininas?

\footnotetext{
1 Prioritariamente um esporte olímpico feminino em nível de competição, a GR ganhou uma versão masculina desenvolvida no Japão durante os anos de 1969. Ainda que hoje a GR masculina possua um conjunto de regras claras e específicas, a Federação Internacional de Ginástica (FIG), órgão que rege esse esporte no mundo, assim como a Confederação Brasileira de Ginástica (CBG), ainda reconhecem a GR como sendo uma prática oficialmente feminina.
} 
Nas próximas páginas organizamos o texto em quatro momentos: no primeiro, apresentamos aspectos metodológicos da pesquisa; logo após, aspectos da pedagogia dos corpos na ginástica rítmica; no terceiro, discutimos os contrapontos entre masculinidades e feminilidades por meio do corpo na GR como um produto de relações processadas historicamente no âmbito de diversas práticas culturais e sociais; por fim, apresentamos algumas considerações, ressaltando a importância de debater as questões de gênero, de beleza e técnicas na GR para compreendermos diferentes formas de ser mulher em nossa sociedade.

\section{UMA ABORDAGEM METODOLÓGICA}

Realizamos observações de treinamentos e competições no interior de Santa Catarina registradas em diário de campo (DC) e entrevistas com uma ginasta (G1) e duas treinadoras (T1 e T2) de uma equipe catarinense de GR, durante o período de 2008 e $2014 .^{2}$

Como sugere o método etnográfico, partimos de uma experiência prolongada em uma equipe de ginástica rítmica, analisando o que ginastas e treinadoras faziam e diziam sobre suas práticas, escolhas, gostos, conceitos. Isso exigiu conviver e compartilhar com elas hábitos e modos de vida, por meio de "una mirada desde adentro" (GARCÍA; CASADO, 2008, p. 47, grifos dos autores) preocupada em alcançar a compreensão dos significados e a multiplicidade de estruturas complexas presentes nesse contexto.

Dentre os sujeitos que participaram deste estudo, encontram-se: a) duas treinadoras ex-ginastas observadas e entrevistadas em 2008 (durante uma semana) , $^{3}$ 2010 (entre março e outubro) ${ }^{4}, 2013$ (entre março e novembro) ${ }^{5}$, contando, na última incursão do campo, com trinta e três e trinta anos. As ginastas observadas nesse mesmo período possuíam entre seis e dezessete anos e dedicavam-se diariamente aos treinamentos; enquanto a entrevistada no ano de 2014 possuía dezenove anos e havia participado da seleção brasileira adulta de GR. Todas as anotações e entrevistas (gravadas e transcritas) constituíram o material bruto, na forma textual de uma descrição densa, como salienta Geertz (2008).

O critério de escolha dos sujeitos investigados considerou o nível técnico das atletas, a presença nos treinamentos e/ou a participação nas competições analisadas com o intuito de compreender as relações entre ginastas de iniciação e de alto rendimento, além de aspectos referentes à construção dos corpos.

Clifford Geertz (2008) e Pierre Bourdieu (2004) foram importantes para a conformação das bases teórico-metodológicas do trabalho, em especial na compreensão do corpo e de suas relações técnicas e estéticas. No encontro entre os dados e as interlocuções teórico-metodológicas construiu-se um conjunto de categorias mutuamente relacionadas, procurando circunscrever uma pedagogia dos corpos femininos, indicando ideias que fazem sentido em consonância com a

\footnotetext{
2 Essa pesquisa foi aprovada pelo Comitê de Ética, sob o registro CAAE: 11862612.4.0000.0121.

3 Foram realizadas observações contínuas em uma competição estadual, no transporte, nos treinamentos (durante a competição e após o evento) e no alojamento.

4 Foram observadas, aproximadamente, vinte sessões de treinamento e quatro campeonatos estaduais de ginástica rítmica em SC.

5 Foram observadas em torno de vinte sessões de treinamento, uma competição estadual e duas nacionais em que houve participação dos sujeitos pesquisados.
} 
interrogação formulada. Essas categorias foram elencadas por meio de leitura dos dados do campo e apresentam aspectos comuns que apontam a compreensão do fenômeno estudado e a interpretação de seus sentidos. A análise, portanto, foi feita a partir das estruturas de significações (códigos estabelecidos) e determinada por sua base social e importância, como sugere Geertz (2008).

\section{PEDAGOGIA DOS CORPOS FEMININOS: UMA CONFIGURAÇÃO GÍMNICA}

As distintas práticas e instituições sociais (família, mídia, escola, esporte) inscrevem diferentes marcas generificadas nos corpos, ensinando-os costumes, valores, crenças, maneiras de se perceber, ser e de agir como mulher ou como homem em um determinado espaço e tempo.

Feminilidades e masculinidades são constituídas por processos culturais e estão ligadas à produção de identidades diversas e plurais de mulheres e homens no interior de relações e práticas sociais (GOELLNER, 2007). Estas não somente constituem os vários tipos de mulheres e homens, mas também produzem formas de como as instituições sociais são organizadas e percebidas (SILVA; SOARES; RIBEIRO, 2005). As práticas sociais, o esporte entre elas e com destaque, ensinam mulheres e homens a reconhecer-se como tais em sociedades e grupos a que pertencem.

No caso da GR, procura-se ensinar modos e técnicas para cuidar do corpo de forma simultaneamente "natural" e racionalizada. As prescrições ganham força em um discurso que se manifesta na obsessão pela limpeza. A higiene compõe a educação do corpo ginástico, pretendendo eliminar toda sujeira, como quando observamos que "todas as ginastas se higienizavam antes das refeições (DC, 23/05/2013). As pretensões de limpeza e higiene operam lentamente uma disciplinarização mais abrangente do cotidiano e dos comportamentos, a partir de uma exigência de modelar o corpo.

Georges Vigarello (1996) apresenta que a limpeza protege e reforça o corpo e o uso de suas potencialidades, aspectos que são associados aos propósitos das ginastas: "Antes de iniciar os treinamentos, as treinadoras chamaram as meninas para verem o lixo do banheiro. Uma treinadora solicitou que, uma por uma, entrasse no banheiro para ver a sujeira que elas haviam deixado após o último treino". (DC, 11/03/2013).

Os rituais de pureza e impureza criam uma unidade na experiência, como salienta Mary Douglas (1991), que observa que a "sujeira é [vista], essencialmente, [como] desordem. Não há sujeira absoluta: ela existe aos olhos de quem a vê. [...] A sujeira ofende a ordem. Eliminá-la não é um movimento negativo, mas um esforço positivo para organizar o ambiente" (p. 12). A preocupação com a limpeza relacionada à organização na GR pode ser visualizada ainda no exemplo a seguir: "As ginastas disseram que o bebedouro estava sujo e, após limparem, me chamaram e disseram 'vem ver a água e já anota como nós somos organizadas'." (DC, 12/03/2013).

As crenças de higiene e limpeza traduzem, concretamente, os cuidados necessários ao corpo e suas consequências implicam profundas transformações nos costumes. Não basta apenas cuidar da higiene pessoal, é preciso investir também na aparência. Os inúmeros cuidados com a limpeza do corpo tendem a ser tratados sob 
um intuito de embelezamento presentes em ocasiões como a em que todas "foram ao banheiro várias vezes para se olharem e fazerem poses na frente do espelho." (DC, 14/09/2010), ou, ainda, condizente à condição atlética: "Ginasta não precisa ter muita coisa para mostrar que é boa. Basta ter uma série [coreografia] limpa, ser limpa na maquiagem e na roupa." (T2, 22/09/2008).

Os cuidados de si como requisitos para se obter um corpo condizente à condição feminina levam a admitir que as feminilidades se inserem nos padrões de comportamento, de conduta, de moral, de um dever ser inscrito nos corpos. Para tanto, a ginasta deve fazer uso de tratamentos de beleza, ter cuidados diários com sua apresentação, que são elogiadas pelas treinadoras: "Que linda que você está, passou brilho? Disse a treinadora para uma atleta. [...] A treinadora elogiou a unha pintada de rosa de outra ginasta." (DC, 24/03/2010). O uso de imagens do corpo em certas práticas e produtos de embelezamento desperta o desejo e constitui uma política de controle das condutas largamente utilizada nesse esporte, no qual é preciso cuidar da feminilidade revelada.

Produzem-se corpos femininos em uma espécie de "repetição ritualizada" (ADELMAN, 2003, p. 450), por meio das quais as normas sociais são consolidadas. Dessa forma, constitui-se a partir da formação às vezes ritualística, mas sempre generificada, maneiras restritivas de ser, de se vestir, de gestos técnicos e corporais, assim como suas várias expressões de embelezamento. As feminilidades consistem em regras diretamente impostas por meio dos discursos sobre o corpo vinculados às roupas, às configurações dos corpos, aos comportamentos e condutas e, por fim, aos movimentos corporais.

Estudos como de Susan Bordo podem auxiliar nos detalhamentos do processo de construção de corpos femininos, tanto no sentido da presença que, nas práticas corporais, têm os regimes exaustivos de exercício, dieta, aperfeiçoamentos do corpo, obsessões com a aparência, quanto no que se refere às imagens culturais nas quais tais práticas se apoiam. Como menciona a autora, para alcançar a aparência especificada, exige-se um investimento particular - usar roupas, regular a comida, movimentar-se de forma restrita - tendo como resultado um corpo feminino incapaz de executar atividades fora de sua esfera designada. O corpo, como agente da cultura, é uma poderosa forma simbólica, uma superfície na qual as normas e os controles são inscritos e assim reforçados por meio de linguagem corporal (BORDO, 1997).

A ginasta incorpora os traços convencionais do feminino, exorbita e acentua marcas corporais, comportamentos, atitudes, vestimentas culturalmente identificadas como femininas. Essa gama de elementos estéticos é o que caracteriza a GR e a difere de outras modalidades, como a ginástica artística, como ressalta o discurso nativo:

[...] a GR é um dos esportes mais glamorosos que tem. Pelo fato de você usar um collant com brilho. Você colocar, no coque, um amarradorzinho com frufruzinho. Você ter a maquiagem. A maquiagem conta muito, está cheia de brilho e maquia branco com brilho, com batom vermelho, tic tac com strass, e assim vai. [...] Isso não vale muito na olímpica [ginástica artística]. (T2, 22/09/2008).

Tudo deve combinar entre si e ter uma medida certa: cores, brilhos, tons de unha, aparelhos que podem ser encapados, nuanças do cabelo e, até mesmo, o 
ritmo da música. Faz parte da produção envolver o rosto com cores semelhantes à roupa, ressaltando maquiagem exaltada e extremamente aparente, marcada, ainda, por uma forma de ser bela e feminina. A construção do coque, a manutenção do peso, o sorriso, são práticas "naturalmente" exercidas por elas e que atendem às normalidades e exigências do subcampo ${ }^{6}$.

O embelezamento deve, portanto, ser realizado priorizando regiões específicas: rosto, cabeça, mãos e pés, com atenção especial às unhas e outras partes que estão em maior evidência, como é possível analisar em um trecho do diário de campo: "A treinadora perguntou à sua atleta se ela havia feito a unha do pé. Ela respondeu '“Claro que não'. Disse que a última vez que ela fez perguntaram se ela era jogadora de futebol". (DC, 21/05/2010). É considerado vergonhoso não se adequar às demandas demarcadas como femininas, mas é aceitável quando as imperfeições não estão à amostra, como as unhas dos pés cobertas pelas sapatilhas ${ }^{7}$ durante os treinamentos e competições.

Às ginastas são impostas normas corporais em busca de uma harmonia corporal, porém, esconder-se é imperioso quando surgem sinais indesejáveis no corpo, como, por exemplo, obesidade, flacidez ou musculatura vista como exagerada. Os inúmeros cuidados com a aparência se mostram imprescindíveis para certa simetria corporal, conferidos em alguns momentos como: "A treinadora sugeriu à ginasta que ela não usasse meia-calça, mesmo se estivesse frio. 'Ela tem a perna bonita para mostrar. Para mim só usa meia calça quem é gorda'" (DC, 10/05/2013). Carmen Soares e Alex Fraga (2003) explicam que se entranha nos corpos, por meio de um arsenal educativo voltado para a retidão das formas e dos costumes, uma distribuição detalhada do que deve ser vergonhosamente escondido ou orgulhosamente exibido.

Ao mesmo tempo em que o corpo deve estar à amostra nas apresentações, ele precisa estar adequado para tal. Assim, na busca e emprego dos mais sofisticados artefatos de eliminação dos excessos encontra-se a tirania em relação ao corpo, assentada de forma a extirpar as saliências corporais indesejáveis. O que está em jogo é um corpo magro, com contornos musculares, acompanhado do controle de peso, no qual o regime alimentar está presente com regulação recorrente realizada por balança. A ginasta deve pesar-se diariamente e invariavelmente combater 0 excesso de gordura corporal:

As treinadoras colocaram a balança portátil em cima do tapete e, em fila, cada atleta se pesou. Durante a pesagem, uma treinadora comentou brincando "É muita pança"! Duas atletas emagreceram dois quilos e comemoraram entre si. A treinadora então falou, "Eu quero mais". (DC, 11/03/2013).

As preocupações relativas ao corpo foram reforçadas com a introdução de balanças. Como explica Denise Sant'Anna (2012), a balança confirma o aumento da importância de vigiar o próprio peso e o de outros, como se observa em farmácias e salas de ginástica. Uma atleta comentou sobre essa dinâmica na equipe nacional: "Eu tenho exigência de não poder engordar. Se eu engordo 100 gramas eu já levo esporro, é assim". (G1, 08/07/2010). A coerção é substituída pela culpa, nesse caso, 
na cobrança de não estar de acordo com as exigências corporais e de movimento. O que se coloca em discussão é exatamente o controle do apetite que "é meramente a expressão mais concreta da norma geral que rege a construção da feminilidade, de que a fome feminina - por poder público, independência, gratificação sexual — deve ser contida" (BORDO, 1989, apud BORDO, 1997, p. 23).

Esse controle da alimentação é voltado para o ajustamento das formas corporais, quando a adoção de regimes alimentares, utilização de cinturões ${ }^{8}$, ingestão de remédios e laxantes, são legitimados para que seja possível ingressar e continuar na equipe, especialmente no alto rendimento, como comenta uma ginasta: "Ela comia bastante também e depois vomitava e tomava laxante" (G1, 28/01/2014). Isso ocorre porque, como explica Karenine Porpino (2004, p. 124), "a busca por uma estética corporal que ao menos se aproxime dos padrões internacionais da modalidade começa desde a escolha das ginastas para compor as equipes e se mantém durante todo o treinamento com o controle regular do peso".

Observa-se, assim, que na ginástica rítmica, a necessidade de controlar o corpo está ligada à tentativa de evitar falhas técnicas e falta de beleza artística que podem ocorrer pelo excesso de peso. As deformidades estão relacionadas a esse excesso de peso e a busca da composição corporal equilibrada está intimamente vinculada ao princípio da retidão do corpo e da magreza do porte. Parece desperdício de tempo incluir meninas que fujam desse padrão.

A elegância dos movimentos e o espetáculo são produzidos por um corpo que deve ser magro. O extraordinário aumento da gordura corporal, como fator crítico, como espécie de "anomalia de feminilidade" (ADELMAN, 2003, p. 454), recrimina a ginasta, independente, por exemplo, das mudanças hormonais e de crescimento. É frequente que uma ginasta esteja em fase de crescimento, já que inicia a prática de atividade física precocemente, geralmente a partir dos cinco anos de idade, mas isso não impede a contenção alimentar: "A treinadora comentou um caso em que uma ginasta precisava emagrecer porque estava ficando 'com peito', 'gostosa', 'mulherão', mas não necessariamente gorda" (DC, 16/04/2010). Essas transformações corporais foram sentidas pelas ginastas: "Eu não tinha problema com o peso. Agora que eu tenho um pouco. Também a idade vai criando formas no corpo" (G1, 28/01/2014).

Observa-se que a possibilidade de adequação do corpo só é possível quando se ultrapassa as barreiras do corpo feminino, de forma que quanto menos encorpada, melhor. Assim, as meninas são motivadas para se manterem limpas, lindas, magras e femininas, pelas dores que devem aprender a suportar para tornarem-se ginastas belas. Determinadas atividades são estimuladas mesmo que não sejam agradáveis, uma vez que o sacrifício em nome da beleza também é elemento visto como pedagógico. Um momento explícito é na execução do penteado utilizado por quase todas as ginastas: o coque. "Na hora do coque, a ginasta dizia sorrindo: 'Sessão tortura'! [...] Uma atleta comentou sobre a realização do coque: 'machuca muito.' (DC, 21/05/2010).

Estreitas relações se impõem à base de sacrifícios corporais para adequação a um modelo de feminilidade. A dosagem do corpo produzido deve atender aos critérios de beleza desse subcampo, amortizada pelo pagamento do preço de ser mulher.

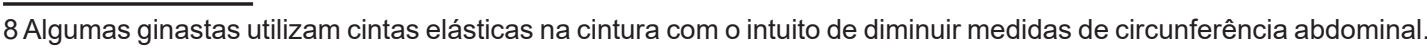


A subjetivação feminina é determinada por uma condição técnica por meio de um trabalho intermitente, compreendendo exercícios físicos e outros métodos que se enquadram nas exigências de conformação corporal. Como resultado de inúmeras técnicas para moldá-lo de modo cada vez mais específico e objetivo, as prescrições e detalhamentos constituem uma "pedagogia dos corpos femininos" (ALBINO; VAZ, 2005 , p. 64, grifos dos autores). Para os autores, essa pedagogia ganha estatuto na medida em que as prescrições de beleza destinadas ao feminino constituem o ser mulher em um lugar e tempos específicos que, uma vez incorporado, fará parte da memória individual e coletiva, tornando-se "natural" e universal, dizendo, assim, sobre uma das formas de ser mulher no tempo presente. No que se refere à GR, as ginastas serão alvos de intervenções, sofrendo controle do corpo por meio de prescrições e aconselhamentos de um dever ser a ser inscrito nos corpos, nos quais estão incluídos os padrões de comportamentos, de conduta, de moral.

As pedagogias do corpo aqui tratadas fazem sentido no interior desse subcampo esportivo, em que técnicas e sentidos criam nos corpos identidades e apropriações, o que nos permite interpretar a ginástica rítmica segundo seus mecanismos de aquisição técnica e estética, imperativa para a educação feminina, resultado de investimento, controle do corpo, educação precisa que dá sentido à composição corporal.

\section{CORPOS FEMININOS EM DEBATE: FEMINILIDADES NA GINÁSTICA RÍTMICA}

Se o esporte é historicamente uma prática social especialmente masculina, por apresentar elementos construídos social e culturalmente, como dominação, controle, virilidade, resistência à dor etc., há modalidades que aparecem como expressão contrária a essa afinidade, mas que, por outro lado, também compartilham dessas características, como é o caso da GR, permitindo a construção e compreensão de feminilidades plurais.

A ordem feminina quanto à adequação estimula a conquista da beleza por meio das ações realizadas pela própria ginasta em seu corpo. Os exercícios prescritos são apresentados como essenciais para um padrão de beleza que se delineia. Uma vez que ela é um atributo dado como intrínseco ao feminino, conquistá-la por meio da realização de exercícios passa a ser um dever. No momento de identificação de beleza, o trabalho paciente e constante prestígio é valorizado: "A treinadora falou para uma ginasta 'Tua música é linda. A gente vai conseguir te fazer ficar leve. Tu vais treinar um monte' [...] 'Tu tens que estar pisando sempre em ovos. Leveza'." (DC, 15/04/2010).

A realização dos movimentos da GR exige trabalho constante dos corpos, esguios e magros, para o qual o balleté técnica corporal elementar de desenvolvimento. Essa forma de dança que remonta ao século treze, configura-se como conjunto de técnicas corporais extremamente importantes e necessárias à GR, e "procura exaltar a leveza, a delicadeza e a beleza, atributos ditos femininos" (GONÇALVES, 2007, p. 11, grifo da autora). As técnicas corporais desenhadas pelas formas do ballet estão presentes nos treinamentos:

O ballet clássico trabalha muito a ondulante, leveza de braço, ponta do pé, que é importante para a ginástica. Só que, o ballet da GR, na verdade, a gente acopla um pouquinho de suavidade do movimento que elas precisam muito e, ao mesmo tempo, a professora de ballet trabalha força e também 
todos os exercícios que a gente põem nas séries. [...] A postura ideal é de uma bailarina. Além de ser muito lindo, faz com que as meninas também fiquem belas dentro de quadra. (T1, 20/04/2010).

O ballet faz parte do treinamento corporal das ginastas e objetiva uma forma de celebração do corpo, ainda muito influenciada por uma concepção clássica de beleza e exibição de corpos ideais. Essa concepção condiz com as formas de corpo idealizadas, que tem referência também em bonecas Barbies, como conta uma treinadora: "Elas têm que ser bailarinas, Barbies. Elas se espelham muito em Barbie, em boneca que se puxa. Elas falam 'minha Barbie faz igual a mim'” (T1, 20/04/2010). A referência às bailarinas e bonecas Barbies demonstra que os corpos das meninas devem corresponder a essas marcas, especificamente pelo fato de serem flexíveis e permitirem a visualização de diferentes formas corporais, tons de pele, cores, vestimentas, acessórios. Suas próprias fantasias relacionadas a esse biótipo são vistas em um momento presenciado na arquibancada de competição: "Uma menina estava na arquibancada com uma Barbie e comentou que conseguia realizar alguns movimentos como a boneca." (DC, 26/06/2010). O mundo das Barbies - em que pese as mudanças ocorridas com o brinquedo nos últimos anos, aumentando o gradiente de possibilidades corporais da boneca - é reconhecido pelas meninas dessa prática esportiva, como se observa também no comentário de uma ginasta ao escutar uma música: "Ela tem a música que eu sempre escuto, Barbie e as doze princesas bailarinas." (DC, 22/05/2010). Essas experiências em torno das bonecas Barbies estabelecem maneiras de como pode ser o corpo, determinado pelas marcas de gênero e produzem formas de pensar, ser, agir e de se relacionar com o mundo (ROVERI; SOARES, 2011).

Como se observa nos depoimentos, o perfil ideal é captado pelas formas bailarinas, pelas Barbies, a partir da leveza, dos movimentos flexíveis e ondulantes, da postura, da qualidade técnica e estética - por tornar os movimentos mais belos. Portanto, a apropriação do ballet é indispensável ao domínio técnico na GR. No entanto, como se vê no depoimento da treinadora, é preciso fazer uma variação do ballet clássico para a ginástica rítmica para que seja realizado um trabalho que exalte a leveza juntamente com a força.

Os elementos de base do treinamento esportivo são essenciais para a obtenção da feminilidade exigida na GR. Assim, a força física é tão importante quanto a flexibilidade, esta última fortemente vinculada à elegância dos movimentos. Desse modo, a eficiência técnica depende da leveza, da flexibilidade, mas também da força que proporciona a execução de movimentos dentro dos limites ideais de determinadas ações:

Eu dou toda a leveza que tem que ter em uma série, mas ao mesmo tempo eu faço força, faço potência. Eu mesclo de tudo um pouco e boto tudo em cima da barra de ballet. [...] O ballet trabalha movimentos bem suaves e delicados, só que assim, eu não posso trabalhar só isso, na minha concepção, porque tem séries minhas que a menina tem que ser toda bailarina e tem séries que eu monto que a coisa é mais agressiva. ( $T 1$, 22/09/2008).

Ao transcender certos limites entre essas duas práticas - a GR e o ballet a realização de exercícios físicos voltados para a GR não estaria cumprindo sua função de manutenção da dessemelhança entre os sexos - a relação de leveza $x$ força -, mas, sim, poderia desencadear o seu contrário. À ginasta é desejável que execute os movimentos com delicadeza e leveza, ao mesmo tempo em que ela 
deve ser forte e ágil. Isso demonstra que as ginastas precisam de muita força para suportar o treinamento, que por trás de toda leveza se esconde força.

Assim, mesmo que a atleta conforme características femininas explicitadas até então, ela precisa superar e suportar aspectos considerados historicamente masculinos, como, por exemplo, a produção de força, resistência à dor e ao sofrimento, aumento da virilidade (coragem), e, sobretudo, diminuição de elementos sensíveis, como a vergonha, o medo, como aparecem nos relatos do campo, quando a treinadora exige que uma ginasta seja lutadora: "Quero uma guerreira dentro da quadra!" (DC, 14/09/2008), ou ainda “'Tu vais ter que perder o medo', disse a treinadora para uma ginasta que não estava acertando um movimento" (DC, 23/03/2010). Para a execução de muitos dos exercícios é preciso que se tenha coragem e perseverança, pois é de conhecimento das esportistas que determinado movimento pode machucar, o que, previamente ao exercício, leva ao medo.

Parece que o perfil da ginasta como subjetivação feminina retrata ideias sobre o corpo, suas formas e capacidades presentes também nas qualificações masculinas, o que nos permite pensar em feminilidades construídas. Mas toma-se, constantemente, o cuidado necessário para não transparecer no corpo que, apesar de toda a sua feminilidade, o esporte lhe ensina e proporciona, por meio do treinamento esportivo, apropriações consideradas masculinas. Isso porque os exercícios dizem sobre os espaços destinados ao feminino e sobre os tipos de atividades próprios a esse gênero, distanciando-se daquilo que é conhecido como próprio do masculino: "Parece um menino fazendo! (na ginástica artística), e aqui não. Pelo fato de precisar ter leveza, tu fazeres ballet e ter os movimentos mais clássicos... e o corpo mais longilíneo e magro. Eu acho que essa é a diferença que já se vê de longe." (T2, 22/09/2008). "A treinadora viu um menino treinando na turma iniciante e comentou: 'Um menino!!! Ele deve ter confundido com a GA'." (DC, 02/04/2013).

Os movimentos de leveza característicos da ginástica rítmica conformam feminilidades que excluem os homens, segundo o discurso nativo, correspondendo à restrição a eles nas competições. Os exercícios não somente delimitam, mas também se configuram como instrumentos para reforçar o esperado socialmente, uma vez que essas atividades estão vinculadas a fins estéticos e ao desenvolvimento de características tipicamente femininas, como quando uma atleta elogia sua melhora na performance ao tornar-se mais leve: "eu era meio bruta, agora eu estou mais leve" (G1, 08/07/2010), ou quando a treinadora reclama do caminhar de uma ginasta por parecer um menino: "ela parece um menino caminhando" (DC, 16/09/2008).

A comparação feita com os esportes mais masculinos e com as atletas que o praticam sugere que utilizam essas comparações para sua autodefinição e para a construção da própria imagem (ADELMAN, 2003). O reconhecimento e a análise dessas afirmações conferem com a colaboração de nossos corpos na reprodução dos gêneros por meio dos quais se impõem, simbólica e fisicamente, práticas culturais. Sobre as ginastas artísticas comparadas às rítmicas, temos um depoimento: "As meninas da ginástica olímpica e os meninos são parecidos. [...] Ginástica olímpica é o que: força, agilidade, é um pouco mais masculino até pelas estruturas delas, até pelo que fica depois. É diferente da GR". (T2, 20/04/2010).

Esses relatos vão ao encontro do que diz Bourdieu (2010) em sua teoria da reprodução, quando afirma que o trabalho pedagógico de construção simbólica não se 
reduz a uma operação meramente performática de nominação que orienta e estrutura representações, a começar pelo corpo; ele se completa em uma transformação profunda e duradoura dos corpos, ou seja, em um trabalho e por um trabalho de construção prática, que exige diferenciação dos usos legítimos do corpo e tende a excluir tudo que caracteriza pertencer a outro gênero. Essas posturas contemplam fortemente as atitudes expressas pelas ginastas, que se empenam em defender a feminilidade de sua atividade esportiva, comparando-a com outros esportes como futebol e ginástica artística.

Além disso, essas experiências apreendem o mundo social e suas arbitrárias divisões, a começar por aquela construída entre os sexos como naturais, evidentes na relação entre homem e mulher. Segundo Bourdieu (2010), a relação entre o feminino e o masculino está no fato de que são as diferenças visíveis entre o corpo feminino e o corpo masculino que, sendo percebidas e construídas, tornam-se fonte indiscutível de significações e valores. Para ele, a divisão entre os sexos faz parecer estar "na ordem das coisas", do que é normal e "natural" a ponto de ser inevitável, sendo "produto de uma construção efetuada à custa de uma série de escolhas orientadas, ou melhor, através da acentuação de certas diferenças, ou do obscurecimento de certas semelhanças" (BOURDIEU, 2010, p. 22).

Pode-se perceber a influência mais oculta, porém mais profunda, de um mundo relacional, tomado por características generificadas, em um universo social que se deixa assimilar nos corpos. Na descrição de formas de lidar com o corpo, Christian Pociello (1995) indica-nos que o campo esportivo feminino retrata um modo engenhoso e maquínico corporal, em que as mulheres passam a buscar um culto ao corpo feminino com precedentes masculinos. Contudo, como podemos observar nos depoimentos, certas características consideradas masculinidades mantêm certa distância em relação aos requisitos técnicos, estéticos e necessários à performance na GR.

Em se tratando das marcas visíveis, o corpo da ginasta é definido por uma simetria feminina, uma assinatura, um gesto, um registro do tipo jovem, firme, forte e flexível, que se exibe de forma milimetricamente reta, alongada, expressiva e bela, sempre reduzido a uma materialidade esquadrinhada por atos de conhecimento. Essa forma de produção de corpo ideal faz duvidar, como sugere Adelman (2003), que o quer que esteja sendo promovido seja um corpo feminino forte e livre; embora possa significar, para algumas mulheres, uma tentativa de resistir ao tipo que representa o corpo feminino como fraco e submisso. Poderia, talvez, ser avaliado como um exemplo de conflitos relativos à definição da corporalidade feminina, ao (re)definir as representações desses corpos, não mais caracterizados apenas como frágeis. Se por um lado o esporte possibilita à mulher a igualdade de gênero, de transgressão da ideia de corpo frágil, por outro, talvez a enquadre em um outro tipo de controle: "aquele que outorga ao corpo das atletas um novo modelo de feminilidade" (TORRI; ALBINO; VAZ; 2007, p. 508).

A construção tradicional da feminilidade cruza com a nova exigência para as mulheres de incorporar os valores masculinos, ressalta Bordo (1997). Porém, não se pode simplesmente juntar as virtudes historicamente femininas àquelas historicamente masculinas para produzir uma nova mulher ou uma nova cultura, salienta a autora. Mesmo corporificadas em personagens, como uma ginasta, o resultado são tipos de 
feminilidades. Em última análise, sua contradição interna transforma-se em formas de ser mulher na ginástica rítmica.

Esses tipos de feminilidades revelam aproximações e distanciamentos de valores tradicionalmente atribuídos a uma identidade feminina e conforma modos e técnicas para cuidar do corpo, tornando-se atitudes consideradas "naturais" pelas pessoas desse subcampo. Assim, o contraste cultural bem definido entre a forma feminina e a masculina, tornado possível pelo uso de instrumentos "condizentes" a cada gênero, reflete, em termos simbólicos, a divisão dualista da vida social e econômica em esferas masculinas e femininas claramente definidas. "Nesse contexto, masculinidade e feminilidade muitas vezes nada têm a ver com o fato de ser um homem ou uma mulher" (BORDO, 1997, p. 104). Isso não significa que padrões ou visão hegemônica sobre a corporalidade feminina não tenham se modificado, lembra Adelman (2003), segundo a qual "o padrão da fragilidade começa a ceder terreno a um novo ideal, mais adequado à noção da 'mulher ativa' que começa a construir-se, nas primeiras décadas do século XX" (p. 448). Entretanto, como menciona a autora, "a cultura de beleza feminina da nossa sociedade atualizou-se a partir da incorporação dessa noção da 'mulher ativa', elaborando novos padrões" (p. 448) que desembocam na atual concepção de corpo, magro e forte, embora não com músculos exagerados, modelo que representa, hegemonicamente, o corpo na GR.

Esses dispositivos de subjetivação feminina, a reprodução, mas também as novas configurações na constituição de um sujeito feminino, o lugar que os sujeitos ocupam e suas representações nesse subcampo, tudo isso implica observar as representações que, ao longo do tempo, acentuam e dispersam as prescrições generificantes.

\section{CONSIDERAÇÕES FINAIS}

O corpo é educado por múltiplos saberes e práticas que vão de rituais de higiene e embelezamento às inúmeras pedagogias que trabalham no controle e modelagem do corpo (SOARES, 2003). Desse modo, o corpo pode guardar a história da qual faz parte e as maneiras pelas quais foi construído, educado, generificado.

A partir de observações e discursos de ginastas e treinadoras observou-se que as diferentes questões referentes à educação do corpo feminino abordadas revelam sua existência como inscrição social. Por problematizar as relações entre corpo e feminilidade, encontrou-se desdobramentos em que modos de ser ginasta vinculam-se a tipos de feminilidades, que nos permitem refletir sobre as diferentes formas de ser mulher nesse esporte.

O conhecimento desse corpo gímnico permitiu, então, por meio de sua objetivação, estabelecer parâmetros de normalidade, a partir dos quais se ditaram modos de tratá-lo e educá-lo. A lista é infinita dos modos de tratar o corpo e as condutas, da forma de andar a de gesticular, a maneira de se portar a de se movimentar em quadra. No entanto, a aquisição das técnicas do corpo depende de uma educação quase sempre muito formalizada, intencionalmente produzida pelo entorno da ginasta, de acordo com um projeto de corpo ideal que demanda leveza, delicadeza, força, flexibilidade, firmeza, precisão e uma incrível capacidade de 
disfarçar, por meio da expressão corporal, principalmente pelo sorriso, medo, esforço e dor que a realização dos movimentos ginásticos e a estética corporal exigem.

Essas diferentes práticas integram-se à formação das ginastas, contribuindo, talvez, para a consolidação de modelos corporais hegemônicos herdados de uma tradição do feminino ao qual corresponde um corpo magro, alongado, projetado de forma singular, sem falhas e deformações corporais, mas também forte, ainda que com pouca, mas definida massa muscular.

Por meio de um sistema complexo de prescrições e detalhamentos, as formas corporais das ginastas rítmicas se constroem, se transformam e se configuram em uma das muitas possibilidades de ser mulher no esporte e em nossa sociedade contemporânea.

\section{REFERÊNCIAS}

ADELMAN, Miriam. Mulheres Atletas: re-significações da corporalidade feminina. Estudos Feministas, n. 11, v. 2, p. 445-465, jul./dez. 2003.

ALBINO, Beatriz; VAZ, Alexandre. "Mulher como deves ser": um estudo sobre a educação do corpo feminino no jornal Dia e Noite. Temas \& Matizes, v. 4, n. 7, p. 63-73, 2005.

ANGHEBEN, Vera. O corpo, a ginástica rítmica e a corporeidade: relações entre o pensar, o falar e o agir com o corpo. Porto Alegre: Nova Prova, 2009.

BOAVENTURA, Patrícia. Técnica, estética, educação: os usos do corpo na ginástica rítmica. 2016. 445 p. Tese (Doutorado em Ciências Humanas) - Centro de Filosofia e Ciências Humanas, Universidade Federal de Santa Catarina, Florianópolis, 2016.

BORDO, Susan. O corpo e a reprodução da feminidade: uma reapropiação feminista de Foucault. In: JAGGAR, Alison; BORDO, Susan (orgs.). Gênero, corpo, conhecimento. Rio de Janeiro: Rosa dos Tempos, 1997. p. 19-41.

BOURDIEU, Pierre. Os usos sociais da ciência: por uma sociologia clínica do campo científico. São Paulo: Unesp, 2004.

BOURDIEU, Pierre. A Dominação Masculina. Rio de Janeiro: Bertrand Brasil, 2010.

BRACHT, Valter. Identidade e crise da Educação Física: um enfoque epistemológico. In: BRACHT, Valter; CRISÓRIO, Ricardo. (org.). A educação física no Brasil e na Argentina. São Paulo: Autores Associados, 2003. p. 13-30.

CORAT, Larissa; ALMEIDA, Marco. Análise da concepção de corpo na Ginástica Rítmica: um estudo dos manuais de 1932 a 1958. Recorde, v. 5, n. 1, p. 1-26, jun. 2012.

DOUGLAS, Mary. Pureza e perigo. Lisboa: Edições 70, 1991.

FÉDÉRATION INTERNATIONALE DE GYMNASTIQUE. Codigo de Pontuación Gimnasia Rítmica 2017-2020. 2018. Disponível em: https://www.gymnastics.sport/publicdir/rules/files/ es RG\%20CoP\%202017-2020\%20with\%20Errata\%20Dec.\%2017.pdf Acesso em: 10 fev. 2019 
GARCÍA, Antonio; CASADO, Elena. La Práctica de la observación participante. Sentidos Situados y prácticas institucionales en el caso de la violencia de género. In: GORDO, Ángel; SERRANO, Araceli (orgs.). Estrategias y prácticas cualitativas de investigación social. Madrid: Pearson Educación, 2008. p. 47-73.

GEERTZ, Clifford. A interpretação das culturas. 13. reimpr. Rio de Janeiro: LTC, 2008.

GOELLNER, Silvana. Jogos Olímpicos: a generificação de corpos performantes. Revista USP, n. 108, p. 29-38, jan./mar. 2016.

GOELLNER, Silvana. Feminismos, mulheres e esportes: questões epistemológicas sobre o fazer historiográfico. Movimento, v. 13, n. 2, p. 171-196, maio/ago. 2007.

GONÇALVES, Michelle. Corpos e subjetivações: o domínio de si e suas representações em atletas e bailarinas. 2007. Dissertação (Mestrado em Educação) - Programa de PósGraduação em Educação, Universidade Federal de Santa Catarina, Florianópolis, 2007.

LOURO, Guacira Lopes. Gênero, sexualidade e educação: uma perspectiva pósestruturalista. 7 ed. Petrópolis: Vozes, 2004.

POCIELLO, Christian. Os desafios da leveza: as práticas corporais em mutação. In: SANT'ANNA, Denise. Políticas do Corpo. São Paulo: Estação Liberdade, 1995. p. 115-120.

PORPINO, Karenine. Treinamento de Ginástica Rítmica: reflexões estéticas. Revista Brasileira de Ciências do Esporte, v. 26, n. 1, p. 121-133, set. 2004.

ROVERI, Fernanda; SOARES, Carmen. Meninas! Sejam educadas por Barbie e "com" a Barbie.... Educar em Revista, n. 41, p. 147-163, jul./set. 2011.

SANT'ANNA, Denise. "Sempre bela". In: PINSKY, Carla; PEDRO, Joana (orgs.). Nova história das mulheres. São Paulo: Contexto, 2012. p. 117.

SILVA, Fabiane; SOARES, Guiomar; RIBEIRO, Paula. (Re)Pensando os corpos das mulheres em contexto de ensinar e aprender. In: ENCONTRO NACIONAL DE PESQUISA EM EDUCAÇÃO EM CIÊNCIAS (ENPEC), 5, Bauru, São Paulo, Unesp. Anais... São Paulo: Abrapec, 2005. p. 1-11.

SOARES, Carmen. Pedagogias do corpo. Labrys: estudos feministas, n. 4, ago./dez. 2003. Disponível em: https://www.labrys.net.br/labrys4/textos/car1.htm Acesso em: 10 fev. 2019.

SOARES, Carmen; FRAGA, Alex Branco. Pedagogia dos corpos retos: das morfologias disformes às carnes humanas alinhadas. Pro-posições, v. 14, n. 2 (41), p. 77-90, maio/ago. 2003.

TORRI, Daniela; ALBINO, Beatriz; VAZ, Alexandre. Sacrifícios, sonhos, indústria cultural: retratos da educação do corpo no esporte escolar. Educação e Pesquisa, v. 33, n. 3, p. 499-512, set./dez. 2007.

VIGARELLO, Georges. O limpo e o sujo, uma história da higiene corporal. São Paulo: Martins Fontes, 1996. 


\section{Apoio:}

O presente trabalho foi realizado com apoio da Coordenação de Aperfeiçoamento de Pessoal de Nível Superior - Brasil (CAPES) - Código de Financiamento 001. This study was financed in part by the Coordenação de Aperfeiçoamento de Pessoal de Nível Superior Brasil (CAPES) e Conselho Nacional de Desenvolvimento Científico e Tecnológico (CNPq), projetos 403624/2016-9; 310115/2017-5; 423773/2018-6. 